Please cite as:

Cranmer, E., tom Dieck, M.C., \& Jung. T. (2017). How can Tourist Attractions profit from Augmented Reality? In. T. Jung \& M. Claudia tom Dieck (Eds.), Augmented Reality and Virtual Reality - Empowering Human, Place and Business, Springer, Forthcoming.

\title{
How can Tourist Attractions profit from Augmented Reality?
}

\author{
Eleanor E Cranmer \\ M. Claudia tom Dieck \\ Timothy Jung \\ Faculty of Business and Law \\ Manchester Metropolitan University, United Kingdom \\ \{e.cranmer\}\{c.tom-dieck\}\{t.jung\}@mmu.ac.uk
}

\begin{abstract}
The benefits, value and potential of Augmented Reality (AR) are widely researched. However, the value of $\mathrm{AR}$ is most commonly discussed in relation to enhancing the tourist experience, rather than generating revenue or economic returns. Although AR promises to add value to the visitor experience and generate associated benefits, the financial implications and revenue model for AR implementation remain uncertain and therefore too much of a financial risk for most tourist organisations, typically Small to Medium Sized Enterprises (SMEs) characterised by limited funding. Thus, using the case of UNESCO recognised Geevor Tin Mine Museum, in Cornwall, UK, this study identifies ways in which tourism organisations can profit from AR implementation. Fifty semi-structured interviews with Geevor stakeholders, analysed using content analysis reveal a number of ways AR can be introduced to increase revenue generation and profits, therefore filling a gap in research and minimising the risk for managers and practitioners considering AR implementation.
\end{abstract}

Keywords: Augmented Reality, Tourism, Revenue Model, Business Model

\section{Introduction}

Throughout the $20^{\text {th }}$ Century the emergence of new adaptive and interactive technologies changed the tourism industry completely (Buhalis and Law, 2008). Technologies have revolutionised travel behaviours, such as decision making and information searching (Wang et al., 2014), transforming traditional business channels and value networks (Buhalis, 2003; Livi, 2008). To remain competitive and financially viable, it has been argued tourist organisations must pursue new ways to provide enhanced (Neuhofer et al., 2014; Tussyadiah, 2014), enriched and unique experiences (Leue et al., 2014; Yovcheva et al., 2013), while offering value adding services (GarciaCrespo et al., 2009). 
For decades, tourism has been considered a tool to stimulate and improve the economy (Ko and Stewart, 2002), thus in the modern age, this has progressed to include the adoption of, and investment in new technologies. It is now advised organisations that fail to adopt modern technologies, such as Augmented Reality (AR), will not remain attractive and competitive (Han et al., 2014; Tscheu and Buhalis, 2016). Hereby, it is argued future competitive advantages are built around the effective use of technologies that add value to the tourist experience (Carlsson and Walden, 2010; Cranmer et al., 2016; Deloitte,2013).

AR has gained much research attention within tourism, for its proven ability to enhance the tourist experience (Garcia-Crespo et al., 2009; Leue et al., 2015), adding value (Cranmer et al., 2016), and creating unique and memorable experiences (Yovcheva et al., 2013). It is widely acknowledged AR creates richer, more immersive content enhancing user's interaction with and perception of the world and thus presents many opportunities to enhance experiences. However, despite many studies exploring and reporting the value of $A R$, the majority fail to identify and determine its financial benefits and economic potential. Therefore, in contrast to expectations, the adoption and integration of AR has been much slower than predicted (Chung et al., 2015). It is argued one reason for this is the absence of research identifying how AR can be introduced to improve profit potential and create revenue streams. Research is yet to bridge the gap between technological potential and actual value adding economic benefits. Therefore, this study attempts to progress understanding about how tourist organisations can implement and profit from AR by providing new insight, which will reduce the risk associated of AR technology adoption, and help mangers and practitioners to better understand ARs financial value, benefits and potential.

\section{Literature Review}

\subsection{Augmented Reality in Tourism}

Technology has had a profound effect on tourism, strengthening the need for organisations to find new ways to increase their presence and therefore competitiveness (Tscheu and Buhalis, 2016). Proliferation of technology, and increased smartphone ownership has revolutionised the way tourists' access and explore information (Jung et al., 2015). Tourists, now demand 'info-cultural-tainment' experiences, combining leisure, entertainment, culture, education and sociability (Palumbo et al., 2013). As a result, an increasing number of tourist attractions have begun to explore the use of AR to enhance visitor interactions with, and perceptions of their real-world environment (Roesner et al., 2014). Research praises AR for its ability to allow tourists with limited knowledge of an area to naturally and realistically experience it (Chung et al., 2015; Martínez-Graña et al., 2013), providing tailored and personalised information (Kounavis et al., 2012; Kourouthanassis et al., 2015) and enhance the tourist experience (Kounavis et al., 2012; Marimon et al., 2014).

A study by Palumbo et al. (2013) found AR increases visitor numbers and provides organisations with more scope to reach wider audiences (Chung et al., 2015; KennedyEden and Gretzel, 2012). Moreover, Chung et al. (2015) identified AR offers destinations and attractions a way to differentiate themselves and increase competitive advantage. In addition to this, it is argued simply that technology attracts tourists 
(Lashkari et al., 2010), because it offers added value to the user (Kounavis et al., 2012), facilitating seamless exploration of their surroundings (Yovcheva et al., 2012), thus extending their learning experience (Yuen et al., 2011). As well as this, implementing AR introduces many marketing opportunities, allowing destinations to come to life, giving visitors a better understanding of what to expect and therefore aiding in decisionmaking and planning processes (Yovcheva et al., 2012; Hassan and Jung, 2016). Many of these findings imply AR could have a positive economic benefit, such as increasing competiveness and therefore, visitors numbers. But, the majority fail to articulate ARs positive profit potential, by failing understand how potential can be translated into economic value. Hence, the financial implications of AR remain too unclear and therefore present too much risk for tourism SMEs.

As a result, contrary to expectations, adoption of AR has been slower than anticipated (Chung et al., 2015), although, it is still argued adopting and investing in modern technologies is a necessity for attractions to remain competitive (Tscheu and Buhalis, 2016; Jung et al., 2015) and economically sustainable (Cranmer et al., 2016). The tourism industry currently lacks a framework or model to aid practitioners and managers to effectively implement AR. Research exploring Business Models (BMs) and Revenue Models (RM) for AR in tourism is scarce, and is currently delaying widespread adoption, implementation and exploration of ARs full potential (Cranmer \& Jung, 2014). To provide insight and progress one step closer to meaningful and wide scale adoption of AR in tourism, this study will identify how ARs potential can be translated into economic value.

\subsection{Augmented Reality Revenue Model}

BMs play a crucial role in helping secure and expand competitive advantage (Johnson et al., 2008), telling the story of how organisations intend to create and sustain profits (Magretta, 2002). BMs focus on creating value and capturing returns from that value (Chesbrough, 2007). Stakeholder collaboration is vitally important to successfully implement new technologies (Al-Debei and Avison, 2010), especially in the tourism context which is characterised by large and complex networks (Livi, 2008). However, the economic value of AR for tourism is undefined, and as a result, organisations remain unsure how to implement the technology to add value to the visitor experience while generating economic return. The potential to add value by implementing AR is widely researched, but, the majority of studies explore ARs value from a visitor perspective, rather than how it can be adopted to generate profit or create additional revenue. An AR RM is currently missing from research, despite the fact it has been argued "a better business model often will beat a better idea or technology" (Chesbrough, 2007, p.12).

In a study exploring the value creation process of $A R$ at Cultural Heritage $(\mathrm{CH})$ sites, earning profits was identified as the most important outcome of AR implementation from a developers perspective, and "varying business models are currently available on the market" (Tscheu and Buhalis, 2016, p. 612). However, no AR specific BMs in a tourism context have been identified within existing research and it remains a clear BM for AR is yet to crystallise (Cranmer and Jung, 2014; Kleef et al., 2010).

Nevertheless, Inoue and Sato (2010) propose several potential ways to generate revenue from AR. However, these mainly adapt existing BMs, and are thus not designed for AR and more specifically the tourism context. On this note, Kleef et al. (2010, p.4) stated 
"value is the key concept of a business model, it is what a business trades with its customers", but suggested in the case of AR, the value is likely to be non-financial. In the context of tourist organisations, often SMEs faced with limited budgets, Tscheu and Buhalis (2016) suggested shared RMs are most suitable, but they do not outline or define how this could work in reality. Therefore, this study will attempt to explore potential RMs for AR implementation, using the case of UNESCO recognised, Geevor Tin Mine Museum, Cornwall.

Geevor is a publically funded organisation, Geevor face increasing pressure to secure additional revenue streams whilst improving the visitor experience and modernising its appeal. Although each CH site is different (Tscheu and Buhalis, 2016), the study will identify potential AR RMs, with the aim of providing practical guidelines for practitioners and managers to identify how AR could be implemented to generate financial returns.

\section{Methods}

Geevor was used as a case study to understand the ways in which stakeholders perceived AR could be introduced to improve the visitor offer, while generating revenue. Stakeholder analysis was performed, identifying five stakeholder groups; 9 of Geevors internal stakeholders (G), 6 Tourist Bodies (B), 3 Tertiary groups (T), 2 local Businesses (L) and 30 Visitors $(\mathrm{V})$. In total, 50 semi-structured interviews were conducted with members of these groups, between March 2015 and February 2016. Due to the exploratory nature of the study, a semi-structured interview approach allowed the freedom to add to and extend questions (Saunders et al., 2012), providing more flexibility and increasing the quality of data (Gillham, 2005).

Sampling is often chosen on the basis of employing methods that source respondents to best meet the overall aims of research. Importantly, "the sample must be appropriate and comprise participants who best represent or have knowledge of the research topic" (Elo et al., 2014, p.4). Therefore, different sampling methods were employed; nonprobability sampling was used to interview all stakeholder groups except visitors, where it was more practical to employ convenience sampling. Prior to interviews respondents were shown a short AR video demonstration and provided with an AR information sheet, to ensure their knowledge of AR was proficient to adequately participate in the interview. All interviews were recorded and transcribed and data were analysed using content analysis.

Regarding the profile of visitors, the majority $(60 \%)$ identified themselves as 'very much' or 'much' with regard to their technical savviness, suggesting they are regular users of technologies such as smartphones and tablets, and $83 \%$ owned a smartphone (and those who did not often said they had a tablet). With regard to all other stakeholders, Table 1 demonstrates internal, tertiary, bodies and business stakeholder profiles including their organisation, position, and prior understanding of AR.

Table 1. Stakeholder Respondent profile 


\begin{tabular}{|c|c|c|c|}
\hline Code & Organisation & Position & $\begin{array}{c}\text { Prior knowledge } \\
\text { of } A R\end{array}$ \\
\hline G1 & Geevor & Trustee & Moderate \\
\hline G2 & Geevor & Chair of Trustees & Moderate \\
\hline G3 & Geevor & Marketing Officer & Low \\
\hline G4 & Geevor & Learning Officer & Moderate \\
\hline G5 & Geevor & Mine Development Officer & Low \\
\hline G6 & Geevor & Mine Guide & Low \\
\hline G7 & Geevor & Curator & Low \\
\hline G8 & Geevor & IT Manager & High \\
\hline G9 & Geevor & Mine Manager & Moderate \\
\hline B1 & Cornwall Council & Cultural Programme Officer & Moderate \\
\hline B2 & Visit Cornwall & Chief Executive Officer & Moderate \\
\hline B3 & Cornwall Museum Partnership & Chief Executive Officer & Moderate \\
\hline B4 & Cornwall Museum Partnership & Development Officer & Moderate \\
\hline B5 & (Freelance) & Museum Marketing Expert & High \\
\hline B6 & Cornwall National Trust & General Manager & Moderate \\
\hline T1 & University of Falmouth & University lecturer & High \\
\hline $\mathbf{T 2}$ & University of Falmouth & University Professor & Moderate \\
\hline T3 & St Ives Secondary School & Secondary school teacher & Moderate \\
\hline LB1 & Count House café & Assistant Manager & Moderate \\
\hline LB2 & Geevor Shop & General Manager & Low \\
\hline
\end{tabular}




\section{Findings}

\subsection{Secondary Revenue Generation}

Stakeholders strongly believed AR could be used to generate secondary revenue, through increased spend both on-site and in the local area, resulting from increased customer retention. It was considered the more time visitors spent on site, using and enjoying AR, the more likely they would spend money, such as staying to enjoy lunch in the café or having afternoon tea. In this way, LB1 hoped AR would encourage visitors to "come to Geevor for the day...I am trying to get double sale or tripe sales". It is believed AR would give visitors more to do, while enhancing their experience and therefore enjoyment. In turn this would increase the time they spent on site and thus likelihood to visit the café for refreshments.

Similarly, with regard to the on-site shop, stakeholders suggested AR would increase visitors' engagement and understanding of the exhibits, therefore increasing their likelihood to purchase items, such as books in the shop to continue and improve their learning experience. It was considered AR would help strengthen the connection between the museum experience and the products for sale in the shop. G7 for instance commented "in the mineral gallery...you could have one small notice saying many of these specimens can be seen and purchased in the shop". In this way, it was considered AR would link directly to the on-site businesses, encouraging visitors to go in, instead of bypassing them. LB2 extended this further, suggesting advertising products throughout the museum experience would not only help drive traffic, retain customers and increase sales, but also increase awareness and interest in local traditions and customs. It was considered if used in this way, AR would be particularly beneficial during low season when the site is quietest, to help combat issues associated with seasonality and customer retention. However, it was acknowledged AR would have to be subtle, careful not to interfere with, or detract from the exhibits.

Stakeholders identified one of Geevors challenges is that visitors underestimate the scale, scope and range of activities offered and often spend longer on site than anticipated. Thus, using AR, G8 and B2 felt people would be more likely to stay even longer because they would appreciate the scale of the attraction. B2 summarised "it is about eating more, drinking more and spending more" suggesting AR would extend visitors dwell time. Equally, B4 pointed out that AR would extend the visitor offer, and likelihood for visitors to spend longer on site, which increases the perception of value for money and therefore again increase their likelihood to spend more in the café and shop. Likewise, B2 claimed if more visitors are coming, staying longer and spending more money it will create a positive change, and increase revenues. These ideas are also mirrored by V22 who said as a visitor, if the experience is more engaging it would increase the likelihood of spending longer on site.

\subsection{Marketing Tool}

The marketing potential and merits of $\mathrm{AR}$ are much discussed within literature, however the use of AR to increase profits has not been previously discussed. Stakeholders strongly acknowledged ARs potential to increase Geevors marketing presence, raising the profile of the site and on a larger scale, Cornwall as a tourist destination. Thus, also attracting more visitors who would spend more at Geevor and 
locally (T2). In this way, AR could give Geevor competitive edge, while helping to attract less specialist and more generalist audiences as well as appeal to younger target groups. Importantly, B5 recognised that if you are doing something for younger markets, you are also doing something to benefit older markets, because they "share the same barriers".

Stakeholders acknowledged simply offering AR would be valuable and drive visits by individuals interested in trying the new technology. In this way, AR could therefore help "seal the deal", influencing and confirming visitors' decision to go to Geevor. B1 suggested AR would attract more visitors, anticipating a good visitor experience thinking "oh that sounds a bit different, I am going to try that out". B1 and G2 perceived, this would have a significant impact on word-of-mouth marketing and recommendations, in turn attracting more people to visit. This is exemplified by V3, V4, V25 and V28 who all claimed they would recommend Geevor, if the AR app provided an enhanced experience.

One of Geevors' key challenges is a lack of funding, therefore if AR had the potential to demonstrate site advancement, innovation and improvement indirectly attracting funders, this would be extremely valuable to Geevor (B3, LB2). In addition, B2 identified the benefit of AR is that it would offer the media something "new" to promote. B5 and G3 also thought AR would increase visitors' likelihood to share their experiences on social media platforms, which would again raise Geevors profile and attracter wider audiences. T2 noted that society is used to instant sharing, and AR should inspire photo sharing, or what people thought of the experience to inspire higher visitor numbers "based on new visits rather than repeat visits". G3 adds this would help increase Geevors online marketing presence. Although T2 raised concern that if some sort of AR experience was available pre-visit, it may have a negative impact and discourage people from actually visiting, because they would feel they had seen it all. But, nevertheless recognised AR would be a good way to potentially increase site engagement and drive visits. AR would however be effective at providing a "wow" factor (G2) incorporated into marketing materials to increase visitor numbers.

\subsection{AR Free or Fee}

A number of considerations arose during interviews. One of the main debates centred around the best and most effective RM to introduce AR at Geevor. Stakeholders were of two minds about whether AR should be offered for free, as part of Geevor trying to better the visitor experience or alternatively whether AR be offered as an extra at an additional fee to the entry cost. Even among stakeholders, who felt AR should be charged at a fee, the amount varied. With regard to visitors, out of 30 visitors interviewed, just over half said they would be willing to pay between $£ 1$ and $£ 5$ to use $\mathrm{AR}$, believing it would make the visit more interesting, entertaining and educational. Although, no ideal cost for AR was identified. Some visitors claimed to have paid for audio guides at other attractions, so paying to use AR would be no different. Most stakeholders agreed that audio guides prove visitors' willingness to pay to have "a bit more information at their fingertips" (B1) and thus would make sense to have a fee attached. However, it was also proposed that the fee could vary at different times of the year and for different target segments. 
On the other hand, just under half of visitors argued they would not be willing to pay a fee to use AR, and it should be offered free as part of Geevor trying to deepen and broaden the visitor experience, and thus better itself. Of these, some suggested however, that if the entry fee increased slightly to cover the costs of AR it would not cause concern. One of the main reasons visitors objected to paying a fee for AR is worry about Geevor becoming too expensive for families, as well as visitors feeling they have to use AR because they have paid for it. This clearly shows that there is no agreement about costs involved in using $\mathrm{AR}$ at $\mathrm{CH}$ attractions thus, proper research is required to ensure that visitors' willingness to pay is fully understood and appropriate strategies adopted.

\subsection{Own or loan devices}

Another debate arising from interviews related to AR pricing structure; whether visitors should have their own devices or if Geevor would provide devices for visitors to loan. Yet, irrespective of the choice made, both could potentially generate revenue. Firstly, if visitors used their own devices Geevor could introduce a charge to download the AR application. Secondly, if Geevor loaned devices to visitors, they could demand a hire fee and deposit. However, both options have financial implications, such as buying and maintaining enough devices to loan to visitors. Equally both options have barriers, for example if visitors used their own devices, it would be based on the assumption all visitors have an AR enabled device, that is fully charged, has enough memory, sufficient connectivity and power to efficiently run the AR application. Visitors without their own AR capable devices would miss out on the experience.

On the other hand, if Geevor were to loan devices, stakeholder recognised the longterm commitment and investment it would involve and issues surrounding security and preventative measures to ensure devices are returned. However, deposit schemes, pre booking devices and tracking devices were proposed by stakeholders as a resolution to such barriers. Visitors largely favoured the idea of loaning devices, claiming they would be willing to pay more to hire a device because it would enhance their experience. Whereas if visitors has to use their own devices and pay to download AR was considered less favourable.

\section{Discussion and Conclusions}

The aim of this study was to explore and understand potential ways AR can be implemented to generate profit. Despite the many benefits AR presents to tourist organisations such as Geevor, its adoption still involves too many uncertainties and therefore financial risk. Therefore, this study aimed to improve understanding by revealing how AR can be adopted to generate revenue, by identifying a number of ways potential AR RMs. However because the study is conceptual, although it identifies potential profit generation methods, using these methods to earn profit is yet to be researched. Nonetheless, the study bridges a gap within current research. At present, the majority of AR studies identify the potential of AR to add value and enhance experiences, rather than generate profitable and financial value. This study adds to the existing pool of knowledge by exploring financial implications of AR implementation. Fundamentally, business is concerned with creating value and capturing returns from 
that value (Chesbrough, 2007). Although value does not have to be financial, for tourist organisations such as Geevor, it is important investment into and adoption of technologies both enhance the tourist experience and generate revenue (Jung et al., 2015), and earning profits is often considered the most important outcome of AR implementation (Tscheu and Buhalis, 2016).

This study reveals a number of potential ways tourist organisations can adopt and implement AR to generate profit. Since this is an underexplored area, the majority of findings have not been previously identified in literature. However, some overlaps with existing research have been identified; for instance stakeholders considered just by offering AR technology, it would broaden and attract wider audiences. This is confirmed by Lashkari et al. (2010) who found technology itself attracts tourists. Similarly, stakeholders identified a number of potential secondary benefits arising from AR implementation that would contribute to increased profits; such as adding value to the visitor experience, increasing and extending the learning experience, as well as providing entertainment and sociability. Such benefits of AR have been previously identified in literature (e.g. Palumbo et al., 2013; Chung et al., 2015; Kounavis et al., 2012), but this study extends understanding identifying how these benefits can contribute to increase profit generation. Stakeholders perceived if visitors have a better experience using AR, they are likely to stay longer on site which would increase their likelihood to spend more money in the café or make a purchase in the shop. In turn, this would create a better reputation for Geevor, broadening the target market, while attracting more visitors, increasing ticket sales and use of local infrastructure, as well as creating more money to invest back into the area. Although previous studies such as Yovcheva et al., (2011) and Hassan and Jung (2016) discuss the marketing potentials of AR, they do not examine how it could generate revenue. Again, interview findings extend understanding; suggesting AR would raise the profile of the site and Cornwall as a tourist destination, increasing visitor numbers, creating a good reputation for the area and enhancing competitiveness.

In addition to this, interviews revealed two debates, firstly should AR be offered free or for a fee? Secondly, should visitors bring their own devices or should Geevor loan AR enabled devices? There was a divide of opinion and although no clear answer was established, the study generates questions that require answers if, and before, AR is to be successfully and sustainably implemented by tourist organisations. For many SMEs, the pressure to adopt and invest in modern technologies increases daily (Tscheu and Buhalis, 2016; Jung et al., 2015; Han et al., 2014), but at present there remain too many uncertainties and therefore a financial risk. The creation and examination of such 'own or loan', 'free or fee' debates create platforms for discussion and demonstrate the need for further research, as well as providing questions for mangers and practitioners considering AR adoption to answer. Therefore, not only does this study extend the existing pool of knowledge and move AR one step closer to meaningful implementation by outlining potential profit generation. It also provides both practitioners and managers with a number of considerations and potential paths to pursue to implement AR to generate a profit, thus minimising financial risk. 
This study has a number of limitations and recommendations for future research. The findings are based solely on a case study of Geevor Tin Mine Museum, therefore minimising their generalisability. Nonetheless, the study identified a number of potential ways to implement AR within tourist organisations to generate profit, however the findings are in no way complete and it is recommended further studies are conducted and the financial outcomes of actual implementation reported. Nevertheless, the study provides insight, of which provide a greater understanding of ARs profit generating potential, thus offering managers and practitioners to learn from and share from the findings.

\section{References}

Al-Debei, M. and Avison, D. (2010). Developing a unified framework of the business model concept, European Journal of Information Systems. 19(3):359-376.

Buhalis, D. (2003). Etourism: information technology for strategic tourism management. Harlow: Financial Times Prentice Hall.

Buhalis, D. and Law, R. (2008). Progress in information technology and tourism management: 20 years on and 10 years after the Internet; the state of eTourism research. Tourism management. 29(4):609-623.

Carlsson, C. and Walden, P. (2010). Supporting Tourists at the Bomarsund Fortress with a Mobile Value Service.' Journal of Information Technology Theory and Application, 11(1):43-56.

Chesbrough, H. (2007). Business model innovation: it's not just about technology anymore. Strategy \& Leadership. 35(6):12-17.

Chung, N., Han, H. and Joun, Y. (2015). 'Tourists' intention to visit destination: Role of augmented reality applications for heritage site. Computers in Human Behavior. 50(2015):588-599.

Cranmer, E. and Jung, T. (2014) Augmented Reality (AR): Business models in Urban Culutral Heritage Tourist destinations. In Pacific Council on Hotel, Restaurant and Institutional Education (APacCHRIE),. Kuala Lumpur, 21st24th May, 2014. APacCHRIE,

Cranmer, E., Jung, T., tom Dieck, M. C. and Miller, A. (2016). Implementing Augmented Reality to Increase Tourist Attraction Sustainability. Dublin Ireland: ARVR Innovate.

Deloitte. (2013). Tourism: Jobs and gorwth: the economic contribution of the tourism economy in the UK.' [Online]. [Accessed on 10th July 2014] http://www.deloitte.com/assets/DcomUnitedKingdom/Local\%20Assets/Documents/Industries/THL/uk-thl-theeconomic-contribution-of-tourism.pdf

Garcia-Crespo, A., Chamizon, J., Rivera, I., Mencke, M., Colomo-Palacios, R. and Gomez-Berbis, J. (2009). SPETA: Social Pervasive e-tourism Advisor. Telematics and informatics. 26(3):306- 315.

Han, D., Jung, T. and Gibson, A. (2014). Dublin AR: Implementing augmented reality in tourism.' In Xiang, Z. and Tussyadiah, I. (eds.) Information and Communication Technologies in Tourism. Wien, New York: Springer Computer Science, 511-523.

Inoue, K. and Sato, R. (2010) 'Mobile Augmeneted Reality business models.' [Online]. [Accessed on 15th October 2013] 
http://www.perey.com/MobileARSummit/Tonchidot-MobileAR-BusinessModels.pdf

Johnson, M., Christensen, C. and Kagermann, H. (2008) Reinventing your business model. 86(2008):50-59. Watertown: Harvard Business School Publ. Corp.

Jung, T., Chung, N. and Leue, M. (2015). The determinants of recommendations to use augmented reality technologies: The case of a Korean theme park.' Tourism Management, 49(2015):75-86.

Kennedy-Eden, H. and Gretzel, U. (2012). A taxonomy of mobile applications in tourism.' E-Review of Tourism Research, 10(20):47-50.

Kleef, V., Noltes, J. and Spoel, S. (2010). 'Success factors for augmented reality business models.' [Online]. [Accessed on 27th August 2014] https://www.interactief.utwente.nl/studiereis/pixel/files/indepth/KleefSpoelNoltes.pdf

Ko, D.-W. and Stewart, W. P. (2002). A structural equation model of residents' attitudes for tourism development.' Tourism Management, 23(5):521-530.

Kounavis, C., Kasimati, A. and Zamani, E. (2012). Enhancing the tourist expeirnce through mobil augmented reality: challenges and prospects.International Journal of Engineering Business Management, 4(10):1-6.

Kourouthanassis, P., Boletsis, C., Bardaki, C. and Chasanidou, D. (2015). Tourists responses to mobile augmented reality travel guides: The role of emotions on adoption behavior.Pervasive and Mobile Computing, 18(1):71-87.

Leue, M., Jung, T. and tom Dieck, D. (2015) 'Google Glass Augmented Reality: Generic Learning Outcomes for Art Galleries.' In Information and Communication Technologies in Tourism 2015. Springer, pp. 463-476.

Leue, M., tom Dieck, D. and Jung, T. (2014). A Theoretical Model of Augmented Reality Acceptance. e-Review of Tourism Research, 5(2014):1-5.

Livi, E. (2008) 'Information, technology and new business models in the tourism industry.' [Online]. [Accessed on 21st October 2014] http://www.gcbe.us/8th_GCBE/data/Elena\%20Livi.doc

Magretta, J. (2002) Why business models matter. 80(2002):86-87. United States: Harvard Busienss School Publishing Corporation.

Marimon, D., Sarasua, C., Carrasco, P., Alvarez, R., Montesa, J., Adamek, T., Romero, I., Ortega, M. and Gasco, P. (2014). Mobi AR: Tourist experiences through mobile augmented reality. [Online]. [Accessed on 3rd November 2014]

http://www.researchgate.net/publication/228979424_MobiAR_Tourist_Expe riences_through_Mobile_Augmented_Reality

Martínez-Graña, A., Goy, J. and Cimarra, C. (2013). A virtual tour of geological heritage: Valourising geodiversity using Google Earth and QR code.' Computers \& Geosciences, 61(12) 83-93.

Neuhofer, B., Buhalis, D. and Ladkin, A. (2014) 'A Typology of technologyenhanced tourism experiences.' International Journal of Tourism Research, 16(4):340-350.

Palumbo, F., Dominci, G. and Basile, G. (2013) 'Designing a mobile app for museums according to the drivers of visitor satisfaction.' [Online]. [Accessed on 3rd 
November

2014]

http://www.wseas.us/e-

library/conferences/2013/Dubrovnik/MATREFC/MATREFC-24.pdf

Roesner, F., Kohno, T. and Molnar, D. (2014) Security and privacy for augmented reality systems. 57, pp. 88-96. New York: ACM.

Tscheu, F. and Buhalis, D. (2016). Augmented Reality at Cultural Heritage sites. In Information and Communication Technologies in Tourism 2016. Springer, pp. 607-619.

Tussyadiah, I. (2014) 'Expectation of Travel Experiences with Wearable Computing Devices.' In Information and Communication Technologies in Tourism 2014. Springer, pp. 539-552.

Wang, D., Xiang, Z. and Fesenmaier, D. (2014) 'Smartphone Use in Everyday Life and Travel.' Journal of Travel Research, p. 0047287514535847.

Yovcheva, Z., Buhalis, D. and Gatzidis, C. (2013) 'Engineering Augmented Tourism Experiences.' In Cantoni, L. and Xiang, Z. (eds.) Information and Communication Technologies in Tourism 2013. Springer Berlin Heidelberg, pp. 24-35. 